\title{
GENERACIÓN DE BIOGÁS A PARTIR DE RESIDUOS ORGÁNICOS DEL COMEDOR DE LA UNIVERSIDAD DE SONORA
}

\author{
Biogas generation from organic waste of the \\ dining room of the university of sonora
}

EPISTEMUS

ISSN: 2007-8196 (electrónico)

ISSN: 2007-4530 (impresa)

Lorena Gabriela Berrelleza Robles ${ }^{1}$

Francisco Javier Armendariz Tapia 2

Onofre Monge Amaya ${ }^{3}$

Maria Teresa Certucha Barragán 4

Sergio Pérez Fabiel ${ }^{5}$

Recibido: 14 de marzo de 2016,

Aceptado: 30 de mayo del 2016

Autor de Correspondencia:

Dr. Francisco Javier Almendariz Tapia

Correo: fjalmendariz@iq.uson.mx

NOMENCLATURA UTILIZADA

Símbolo:

DQO: Demanda química de oxígeno

$\mathrm{C} / \mathrm{N}$ : Relación carbono/nitrógeno

AME: Actividad metanogénica específica

SST: Sólidos suspendidos totales

SF: Sólidos fijos

SSV: Sólidos suspendidos volátiles

SVT: Sólidos volátiles totales

\section{Resumen}

En este trabajo se evaluó el efecto de la biodegrabilidad anaerobia de los residuos sólidos orgánicos por medio de una biometanización para producir biogás como fuente de energía renovable. Para fines de este estudio se utilizaron los residuos sólidos de los alimentos provenientes del Comedor Universitario de la Universidad de Sonora. Las pruebas se realizaron por triplicado en botellas serológicas con volumen de operación de $120 \mathrm{~mL}$, a las que se les adicionó cinco concentraciones de residuos $(0.06$, $0.12,0.24,0.6$ y $1.2 \mathrm{gSVT})$, fueron inoculadas con biomasa metanogénica (0.24 gSSV) y se mantuvieron a $35^{\circ} \mathrm{C}$ por 30 días, la toxicidad de los residuos sobre la biomasa metanogénica se realizó con las mismas concentraciones pero se adicionó $5 \mathrm{~g} / \mathrm{L}$ de acetato de calcio, por último se estudió el efecto del inóculo en cuatro proporciones diferentes de biomasa $(0,1.66,2.66$ y $5.66 \mathrm{gSSV}$ ). Los resultados mostraron una producción de $71 \mathrm{~m} 3$ de metano por tonelada de residuos sólidos orgánicos el cual es superior al reportado en la literatura.

Palabras clave: Biometanización, potencial bioquímico de metano, actividad metanogénica específica.

\begin{abstract}
The effect of the anaerobic biodegradability of organic solid waste through a biomethanization to produce biogas as a renewable energy source was evaluated in this study. For this purpose solid waste food from the University restaurant of the Universidad de Sonora was used.

Tests were performed in triplicate in serological volume bottles were taken with $120 \mathrm{~mL}$ and five different organic loads $(0.06,0.12,0.24,0.6$ and 1.2 gTVS) were applied, also were inoculated with methanogenic biomass $(0.24$ gVSS) and maintained at $35^{\circ} \mathrm{C}$ for 30 days, toxicity tests on the methanogenic biomass was performed with the same concentrations but $5 \mathrm{~g} / \mathrm{L}$ of calcium acetate was added; in addition, finally the effect of inoculum was studied in four different proportions of biomass $(0,1.66,2.66$ and $5.66 \mathrm{gVSS})$. The results showed a production of $71 \mathrm{~m} 3$ of methane per ton of organic solid waste, which is higher than reported in literature.
\end{abstract}

Key words: Biomethanization, biochemical methane potential, specific methanogenic activity. 


\section{INTRODUCCIÓN}

Se define al residuo sólido como aquella sustancia u objeto generado por una actividad productiva o de consumo, de la que hay que desprenderse por no ser objeto de interés directo de la actividad principal [1].

En los últimos años se ha mostrado un gran interés en la aplicación del proceso de digestión anaerobia para el procesamiento de la fracción orgánica de los residuos sólidos urbanos, por la posibilidad de recuperar metano y por el hecho de que el material digerido es similar al compost producido aeróbicamente [2].

La biometanización es un proceso biológico anaerobio que transforma la fracción orgánica (mediante fermentación) en $\mathrm{CH}_{4}, \mathrm{CO}_{2}, \mathrm{H}_{2} \mathrm{O}$ y un material inerte denominado "digestato", que tras un tratamiento posterior, puede ser utilizado como enmienda orgánica por tener propiedades fertilizantes. En el proceso de digestión anaerobia se consigue una reducción del contenido de materia orgánica entre un $45 \%$ y $60 \%$ y requiere de condiciones de operación dentro de unos estrictos rangos de temperatura $[3,4]$.

En este trabajo se estudió la viabilidad de la biometanizacion de los residuos sólidos orgánicos generados en el comedor de la Universidad de Sonora, por lo que se evaluó la cantidad de residuo que puede ser bioconvertida a metano; el efecto tóxico de los RSO sobre las bacterias acetoclásticas y la cantidad óptima de biomasa para mejorar la producción del biogás, contribuyendo así a la sustentabilidad ambiental.

\section{MATERIALES Y MÉTODOS}

El equipo experimental fue ubicado en las instalaciones del laboratorio de Biorremediación del Departamento de Ingeniería Química y Metalurgia de la Universidad de Sonora, edificio $5-C$.

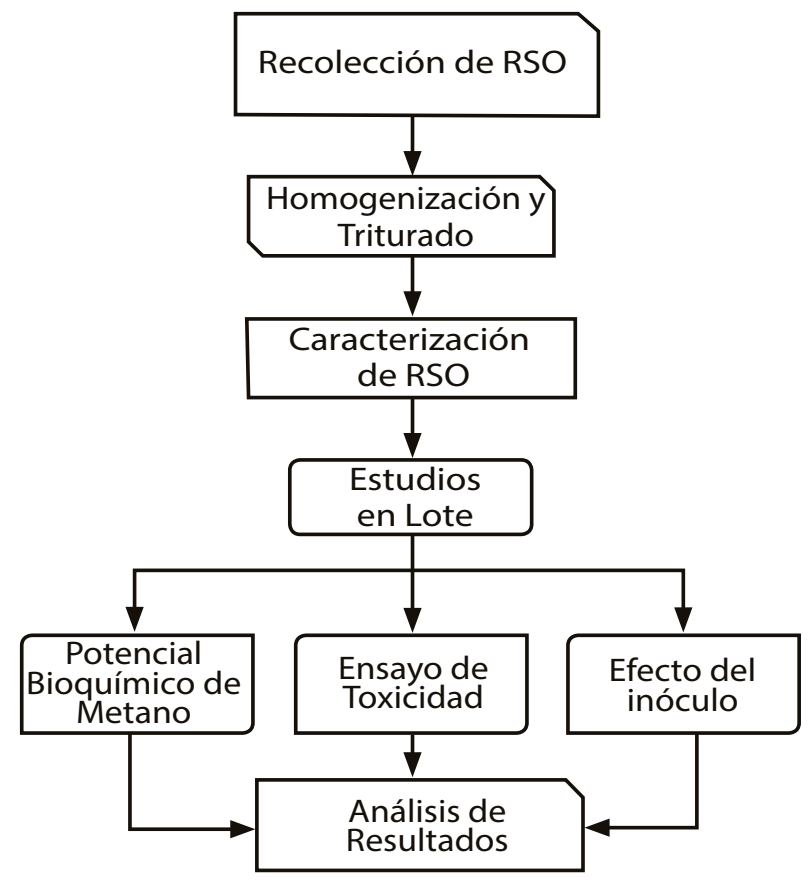

Figura 1. Metodología general.

La primera parte de este trabajo contempla la selección de los residuos sólidos orgánicos (RSO) procedentes del comedor universitario de la Universidad de Sonora, el método de recolección de los residuos sólidos orgánicos fue descrito de acuerdo a la Norma Oficial Mexicana (NMXAA-15-1985). Se obtuvo una muestra de aproximadamente $10 \mathrm{~kg}$. Posteriormente se realizó una trituración en condiciones húmedas utilizando un molino de carne convencional para reducir el tamaño de partícula y obtener un compósito de los residuos (Figura 2). Los lodos anaerobios fueron obtenidos del digestor de la planta de tratamiento de aguas residuales (PTAR) de una industria cervecera.

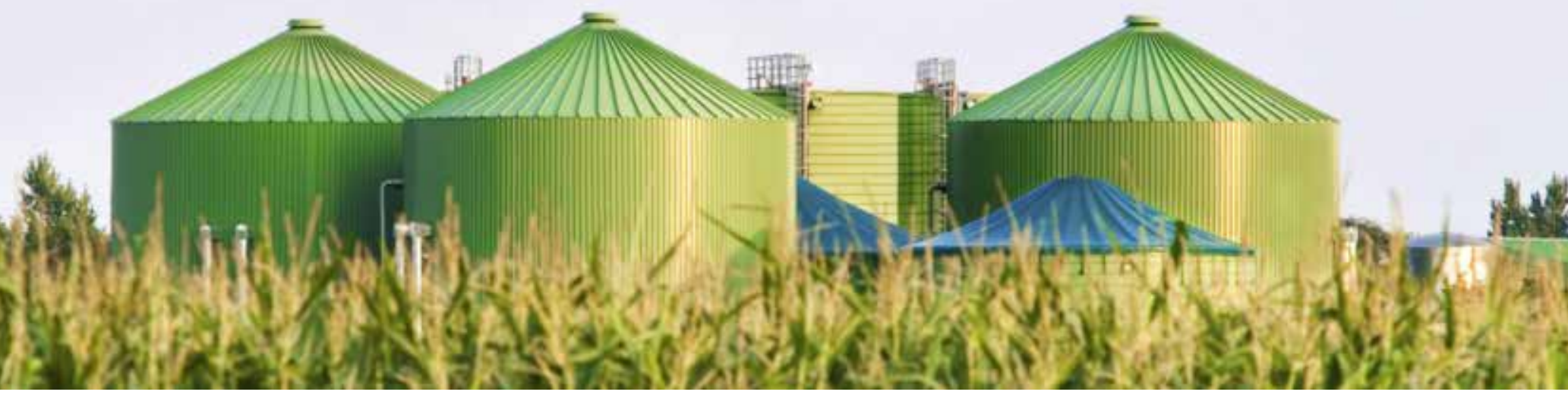


Figura 2. Molienda de los residuos sólidos orgánicos.

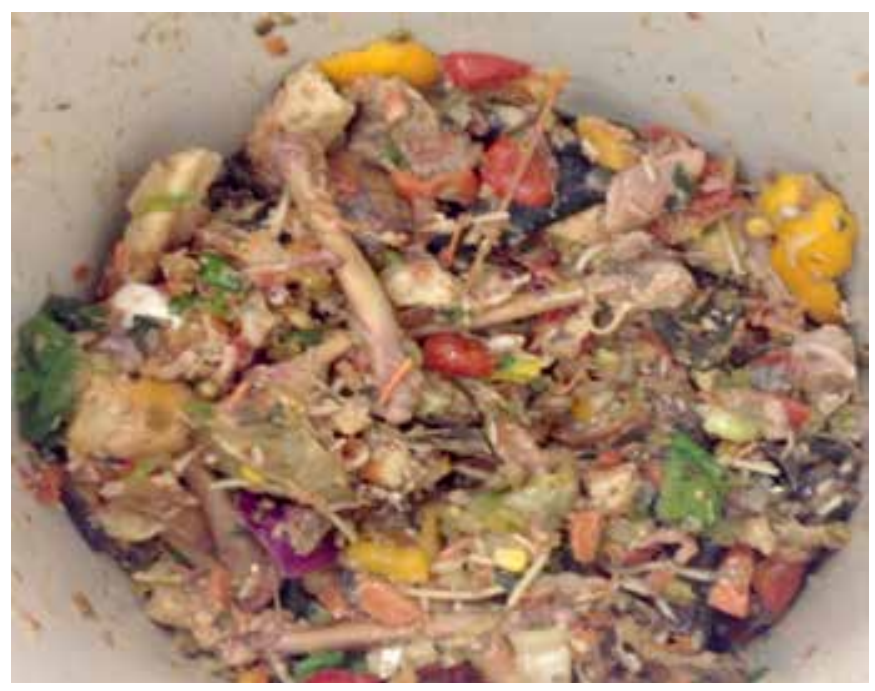

RSO

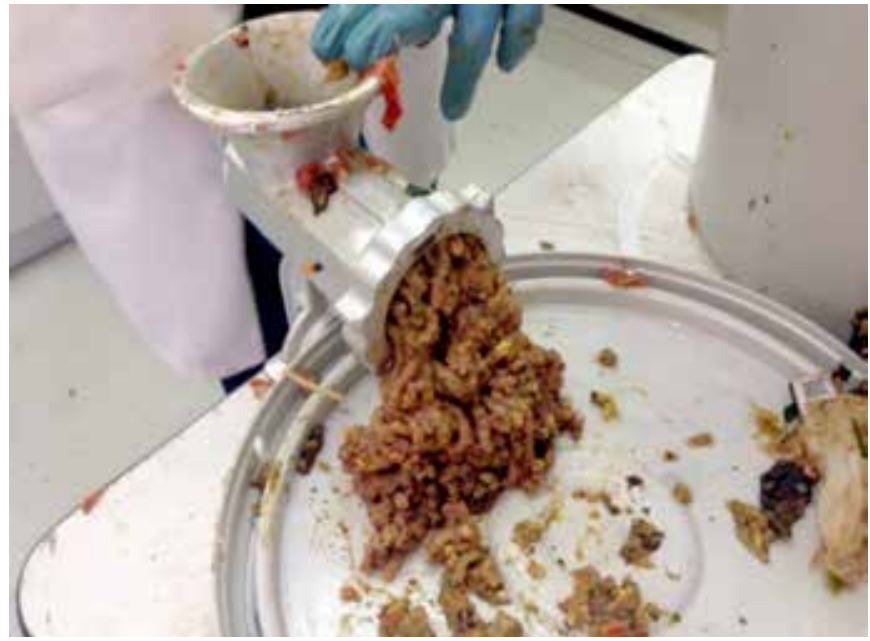

Molienda de los RSO

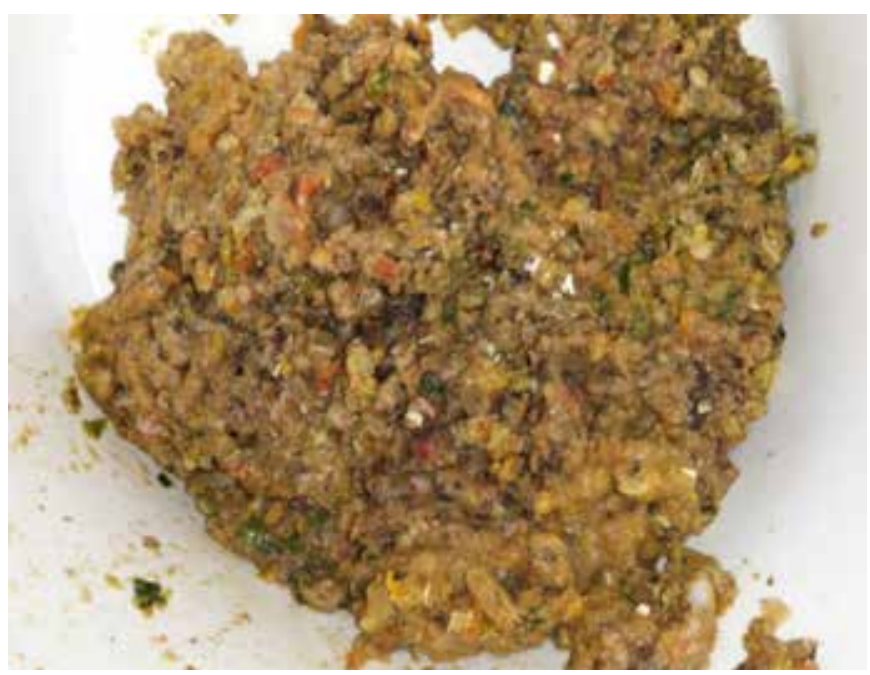

Compósito de los RSO
La caracterización de los residuos sólidos orgánicos se realizó de acuerdo a la Norma Oficial Mexicana y por los métodos estándares. En la tabla 1 se muestran los distintos métodos analíticos utilizados para la caracterización físicoquímica de los residuos sólidos orgánicos.

\section{Tabla 1. Métodos analíticos empleados para la caracterización de los RSO.}

\begin{tabular}{|l|l|}
\hline \multicolumn{1}{|c|}{ Parámetro } & \multicolumn{1}{|c|}{ Método estándar } \\
\hline Sólidos totales (ST) & $\begin{array}{l}\text { Método Gravimétrico- } \\
\text { APHA/SM 2540 }\end{array}$ \\
\hline Sólidos fijos (SF) & $\begin{array}{l}\text { Método Gravimétrico- } \\
\text { APHA/SM 2540 }\end{array}$ \\
\hline Sólidos volátiles totales(SVT) & $\begin{array}{l}\text { Método Gravimétrico- } \\
\text { APHA/SM 2540 }\end{array}$ \\
\hline Grasas & NMX-F-089-S-1978 \\
\hline Humedad & NMX-AA-016-1984 \\
\hline Materia orgánica & NMX-AA-21-1985 \\
\hline pH & NMX-AA-25-1984 \\
\hline Hidrógeno & NMX-AA-68-1986 \\
\hline Nitrógeno total & NMX-AA-24-1984 \\
\hline Carbono & Golueke 1977 \\
\hline C/N & NMX-AA-67-1985 \\
\hline
\end{tabular}

\section{ENSAYOS EN LOTE}

En la segunda parte de este trabajo se llevaron a cabo los ensayos en lote. El compósito de los RSO fue licuado por cinco minutos en una licuadora convencional, para posteriormente ser agregado a las botellas en sus diferentes concentraciones. Los estudios del Potencial Bioquímico de Metano (PBM) se llevaron a cabo en botellas serológicas de capacidad de $160 \mathrm{~mL}$ con volumen de operación de 120 $\mathrm{mL}$ con una relación de carga de los RSO de $0.06,0.12,0.24$, 0.6 y 1.2 gSVT; se inocularon con lodo anaerobio a 0.24 gSSV. Los ensayos de toxicidad de los RSO se realizaron de la misma manera pero las bacterias metanogénicas acetoclásticas se activaron con acetato de calcio agregando $5 \mathrm{~g} / \mathrm{L}$ a cada botella. Para el efecto del inóculo en el PBM la concentración de basura se fijó en 0.24 gSVT y mientras que la adición de biomasa varió de 0, 1.66, 2.26 y 5.66 gSSV, respectivamente. Para los tres ensayos las botellas se incubaron a $35^{\circ} \mathrm{C}, 50 \mathrm{RPM}$ y el metano producido se midió por desplazamiento de una solución de $\mathrm{NaOH}$ al 3\%.

\section{RESULTADOS Y DISCUSIÓN}

Caracterización de los residuos sólidos orgánicos

En la tabla 2 se presentan los resultados de la caracterización físico-química de los residuos sólidos orgánicos (RSO). 


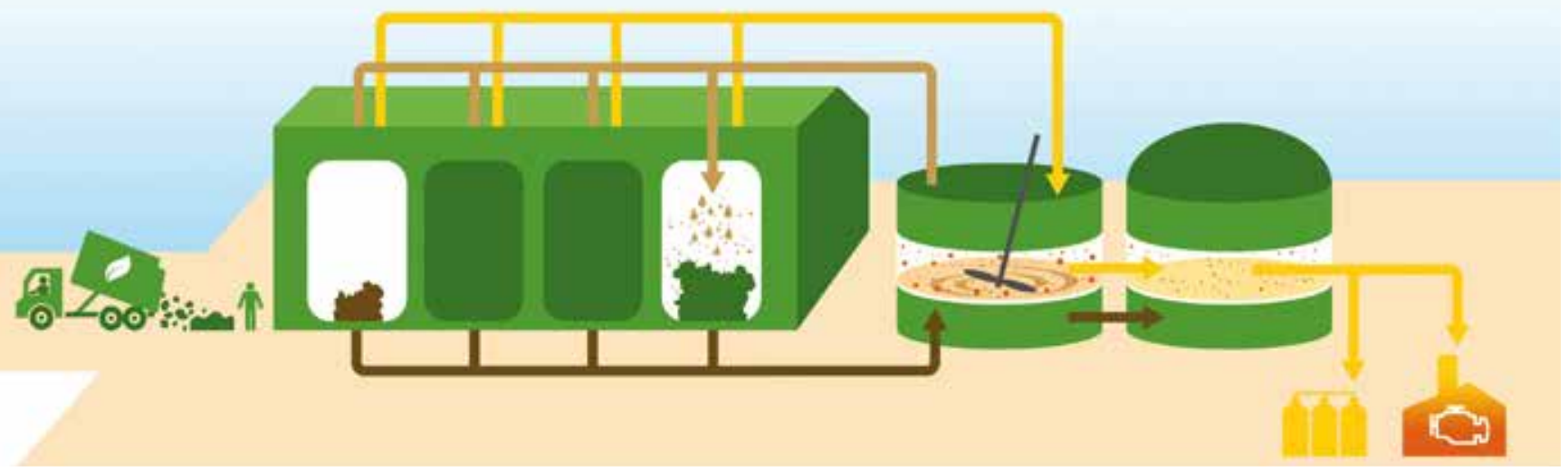

Tabla 2. Caracterización físico química de los RSO del comedor universitario de la Universidad de Sonora.

\section{Parámetro}

Sólidos totales (ST)

Sólidos fijos (SF)

21.20

Sólidos volátiles totales (SVT)

Grasas

Humedad 4.06

Materia orgánica

$\mathrm{pH}$

\section{Hidrógeno}

Nitrógeno (N)

\begin{tabular}{l|l}
\hline Carbono $(\mathrm{C})$ & 9.7 \\
\hline $\mathrm{C} / \mathrm{N}$ & 2.63 (adimensional)
\end{tabular}

La composición de los residuos orgánicos se encontró muy variada de acuerdo al tipo de comida preparada en el día de la recolección. Se encontró gran cantidad de productos de origen vegetal, harinas, productos cárnicos. Se encontró un porcentaje de humedad de los residuos de un $74 \%$ y un porcentaje de sólidos totales de $21.20 \%$ en peso. El alto contenido de humedad y de las fracciones orgánicas (SVT) de los RSO lo hace susceptible para el tratamiento anaerobio, ya que la etapa de hidrólisis que generalmente es un paso limitante en la digestión anaerobia no inhibe el proceso por la alta cantidad de líquidos [5].

\section{ANÁLISIS DE DATOS}

Actividad metanogénica especifica (AME) de los RSO

Es una medida experimental de la capacidad de la materia orgánica y del sustrato para generar metano $\left(\mathrm{CH}_{4}\right)$. En el cual, éste procedimiento indica la cantidad de $\mathrm{CH}_{4}$ como demanda química de oxigeno (DQO) que se produce por unidad de biomasa por día, y que se expresa en $\mathrm{gDQO}_{\mathrm{CH} 4} / \mathrm{gSSV} \cdot \mathrm{d}$ dónde SSV representa la cantidad de gramos de sólidos suspendidos volátiles de la muestra a estudiar. El $\mathrm{CH}_{4}$ producido se calcula por desplazamiento del líquido, en este caso, $\mathrm{NaOH}$ [6].

El volumen de gas producido con respecto al tiempo fue calculado tomando en cuenta la temperatura de la cinética y la presión atmosférica de la ciudad de Hermosillo, Sonora. La AME está descrita por la ecuación 1:

$$
\mathrm{AME}=\frac{\mathrm{m}}{\frac{\mathrm{YCH} 4}{\mathrm{DQO}} \cdot \mathrm{x}}
$$

Ecuación 1

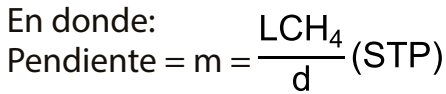

Biomasa $=\mathrm{X}=\frac{\mathrm{gSSV}}{\mathrm{L}}$

Conversión de metano $=\frac{\mathrm{m}}{\mathrm{\textrm {CQH }} 4}=0.35=\frac{\mathrm{LCH}_{4}}{\mathrm{gDQO}}$

Desde el reactor biológico se conecta a una botella invertida que contiene una sustancia alcalina a base de $\mathrm{NaOH}$ al 5\%, por medio de una manguera, la cual funciona como botella de Mariotte; esta botella está tapada con un tapón de caucho, tiene dos agujas hipodérmicas a una de las cuales se le conecta la manguera que transporta el biogás proveniente del reactor. Debido al alto valor de $\mathrm{pH}$ contenido de la botella, el $\mathrm{CO}_{2}$ queda retenido en la sustancia alcalina, mientras que el metano no se disuelve, genera un desplazamiento del líquido, el cual representa el volumen de $\mathrm{CH}_{4}$ contenido en el biogás [7].

\section{Potencial bioquímico de metano}

La producción de biogás en las botellas serológicas fue medido por 30 días. La concentración de los RSO afectó la producción de metano. En la Figura 3 se observa que al incrementar la concentración de los SVT aumenta la producción de metano, logrando una producción máxima de $437 \mathrm{~mL}$ en la concentración de $1.2 \mathrm{gSVT}$ a los 26 días. En las concentraciones de 0.6 y 1.2 gSVT se observó un aumento en la velocidad de producción de metano partir del día 15, posiblemente debido a una adaptación de las bacterias anaerobias a la alta concentración de materia orgánica [8]. 
Figura 3. Evolución de la producción de metano a concentraciones crecientes de los RSO (gSVT).

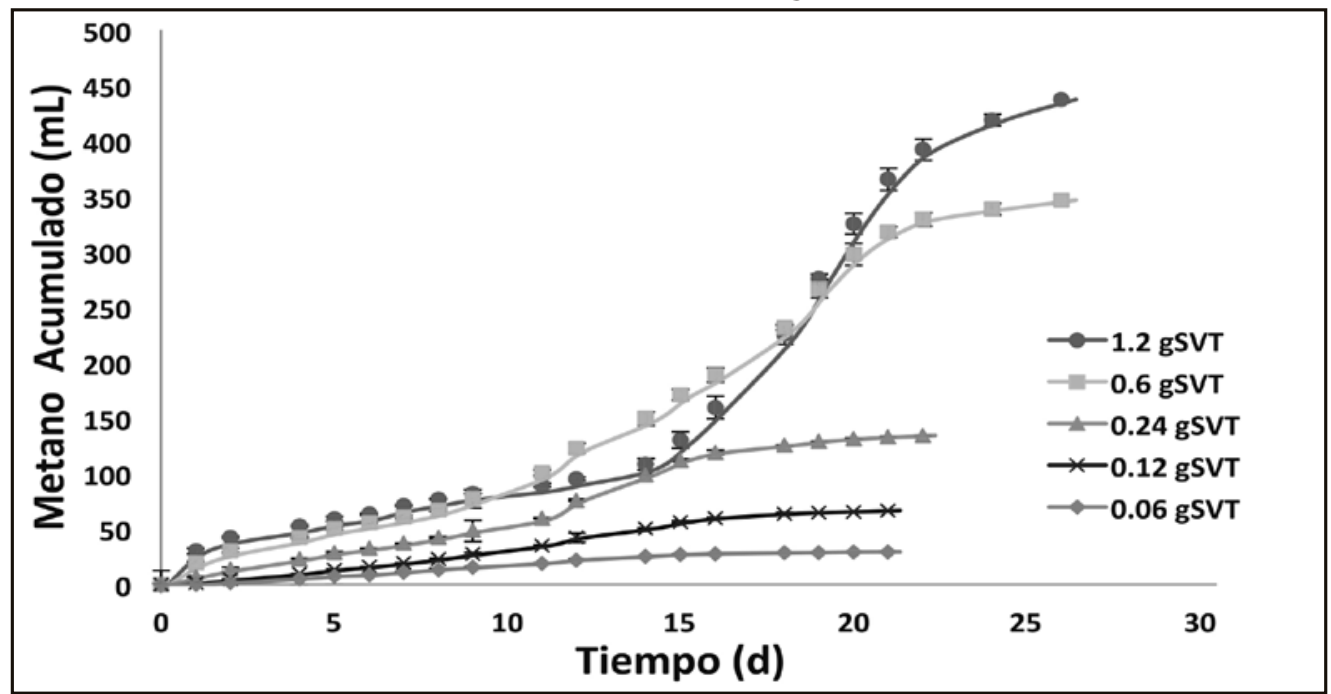

Con base en los volúmenes totales de $\mathrm{CH}_{4}$ producido en cada uno de los ensayos se observó que la producción fue directamente proporcional a las concentraciones de los RSO añadidas hasta 0.6 gSVT (Figura 4), mientras que a la concentración de 1.2 la producción de metano disminuyó (dato no mostrado); y de acuerdo al comportamiento lineal mostrado en la figura 4 se determinó que la producción de $\mathrm{CH}_{4}$ fue de $512 \mathrm{~mL}$ por gramo de SVT inicial de RSO. Tomando en cuenta el contenido de los SVT en los residuos orgánicos se estimó una producción total de $71 \mathrm{~m}^{3}$ de metano por tonelada de RSO. Estos datos son superiores a los reportados por Thomas et al., [9] quienes reportaron una producción de $260 \mathrm{~mL}$ de metano por gramo de SVT así como $40 \mathrm{~m}^{3}$ de metano por tonelada de desechos de alimentos.

Figura 4. Producción total de metano por gramos de SVT inicial de los RSO.

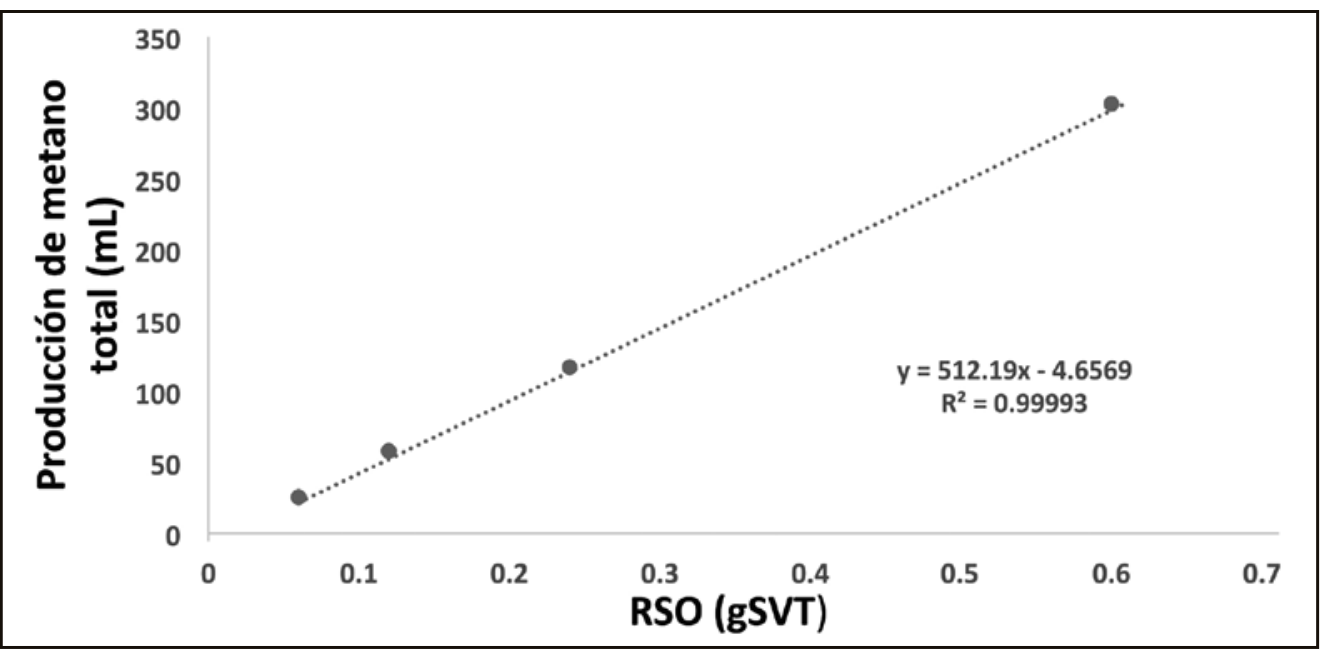

De acuerdo a la producciones exponenciales de metano observados en la figura 3, se determinaron las actividades metanogénicas específicas $\left(\mathrm{gDQO}_{\mathrm{CH} 4} / \mathrm{gSSV} \cdot \mathrm{d}\right)$ para cada una de las concentraciones probadas. En la figura 5 se observa que al aumentar la concentración de los SVT aumenta la actividad metanogénica siguiendo una cinética de primer orden, el cual está descrito por la siguiente ecuación (Ecuación 2):

$$
r A=K(S)
$$

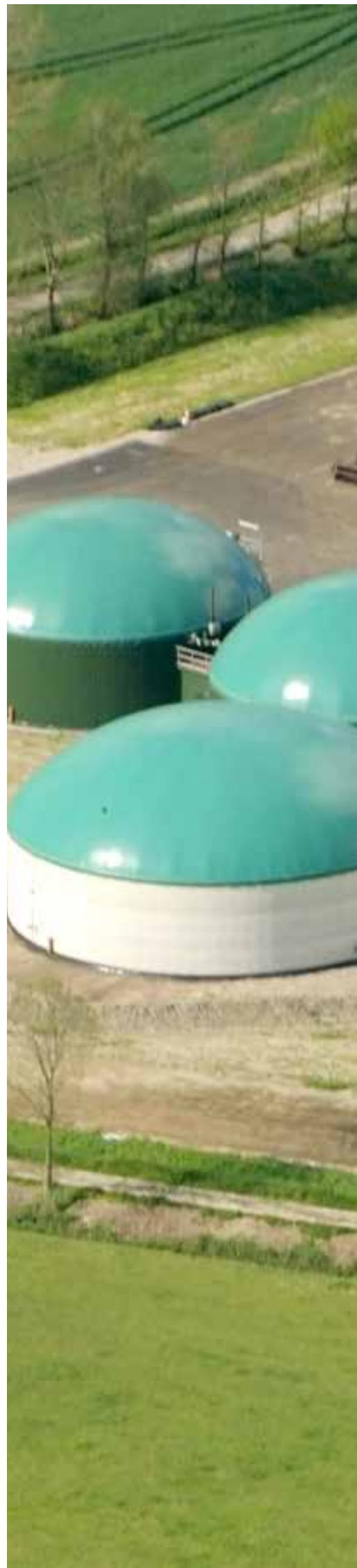


Donde $\mathrm{rA}$ es la actividad metanogénica especifica ( $\left.\mathrm{gDQO}_{\mathrm{CH}_{4}} \mathrm{gSSV} \cdot \mathrm{d}\right)$, $\mathrm{K}$ es la constante de reacción $\left(\mathrm{d}^{-1}\right)$, $\mathrm{S}$ es la concentración del sustrato (gSVT). En este caso, una línea recta con una pendiente igual a $\mathrm{K}$ y un intercepto en el eje "y" igual a cero expresa el efecto de la concentración de los RSO en la actividad metanogénica específica. La figura 5 ilustra la influencia de la concentración de los RSO en la actividad metanogénica en donde la línea recta teórica obtenida con el intercepto igual a cero indica que un modelo de primer orden describe satisfactoriamente los datos experimentales. La pendiente obtenida, el cual representa el valor de la constante de reacción (K) fue de $0.40 \mathrm{~d}^{-1}$ con un ajuste de $\mathrm{R}^{2}$ igual a 0.997. Este modelo de primer orden predice con precisión el comportamiento de la cinética del potencial bioquímico de metano, mostrando desviaciones inferiores al $5 \%$ entre los valores experimentales y teóricos de la AME.

Figura 5. Cinética de primer orden de la AME a diferentes concentraciones de los RSO.

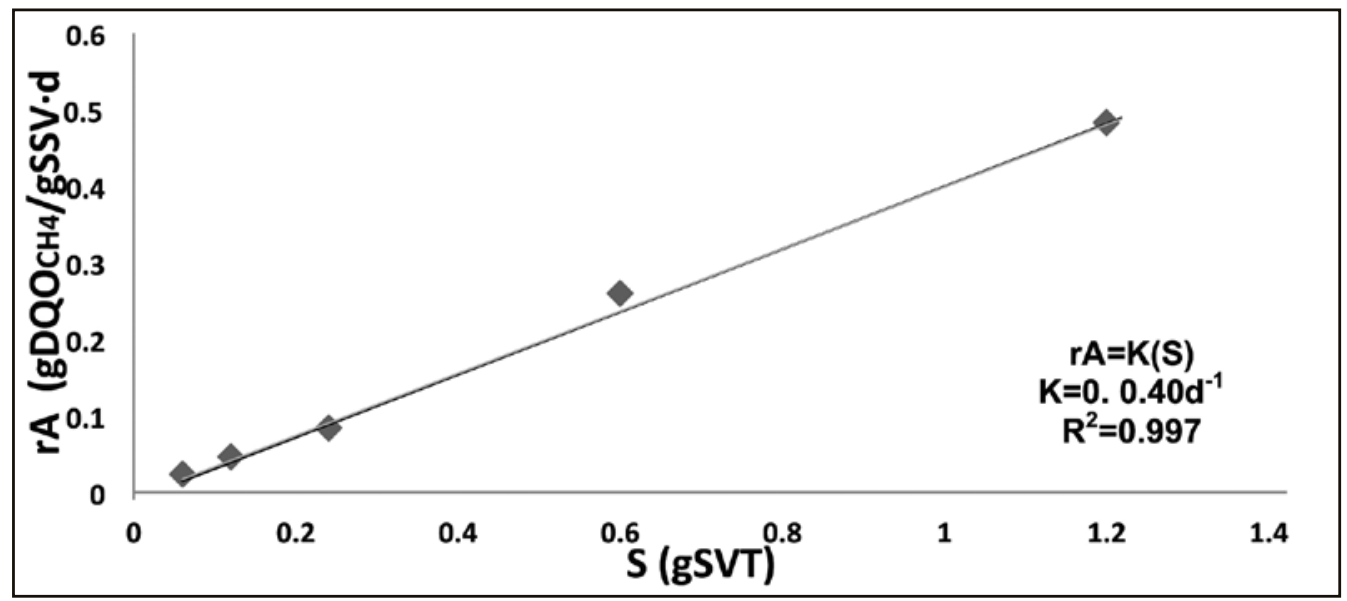

\section{ENSAYOS DE TOXICIDAD}

En la figura 6 se muestra el efecto de la concentración de los RSO en la producción de metano de las bacterias metanogénicas acetoclásticas, en donde a bajas concentraciones (0.06 a 0.24 gSVT) se observó una fase de retardo de siete días, mientras que la fase exponencial comenzó a partir del día 10 con una producción de metano máxima de $300 \mathrm{~mL}$ en la concentración de $0.24 \mathrm{gSVT}$. Por otro lado, en altas concentraciones la fase exponencial empezó a partir del día 14, con producciones máximas de metano de 505 y $663 \mathrm{~mL}$ para 0.6 y 1.2 gSVT respectivamente.

Figura 6. Efecto de la concentración de los RSO en la producción de metano de las bacterias metanogénicas acetoclásticas.

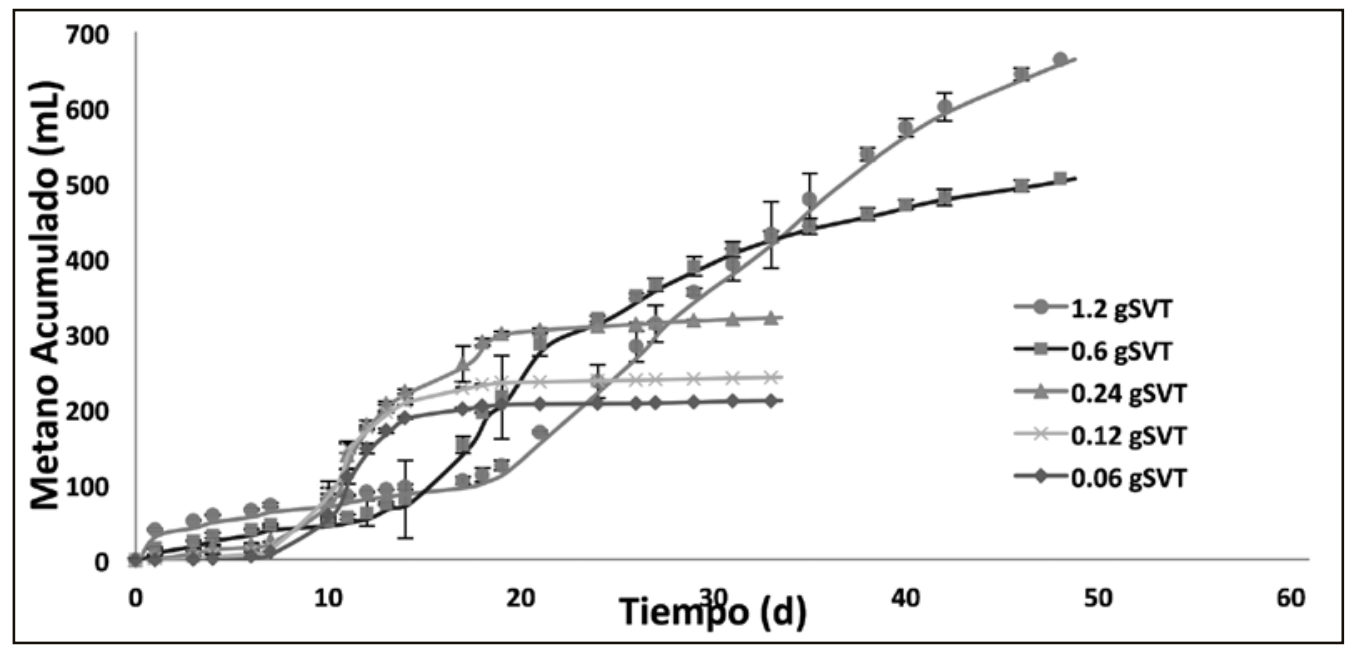


Con respecto a las producciones exponenciales de metano observado en la figura 6 , se determinaron las actividades metanogénicas específicas para cada una de las concentraciones probadas. Las altas concentraciones de los RSO afectó la actividad de las bacterias metanogénicas acetoclásticas. A bajas concentraciones se observó un aumento gradual de la actividad metanogénica con las concentraciones de 0.06 a 0.24 gSVT con un máximo de $0.06 \mathrm{gDQO}_{\mathrm{CH} 4} / \mathrm{gSSV} \cdot \mathrm{d}$, mientras que a altas concentraciones la AME disminuyó un $56 \%$. Los datos experimentales se ajustaron al modelo de Haldane (Ecuación 3) el cual es uno de los más utilizados en pruebas de inhibición por sustrato [10], relaciona la velocidad del crecimiento microbiano con la concentración del sustrato inhibitorio, en este caso, la degradación del sustrato es disminuida por la elevada concentración del mismo y la mayoría de los sustratos no sufren posterior degradación [11]., de acuerdo al modelo se obtuvo una $\mu$ max de $0.50 \mathrm{~d}^{-1}$, Ks de $0.021 \mathrm{~g} / \mathrm{L}$ y una $\mathrm{Ki}$ de $0.46 \mathrm{~g} / \mathrm{L}$ con un ajuste de $\mathrm{R}^{2}=0.9041$. La constante de inhibición representa la concentración alta de sustrato en donde la $\mu=1 / 2$ y Ks representa la concentración baja de sustrato donde $\mu=1 / 2$ [10]. Los valores teóricos del modelo de Haldane fueron estimados mediante la herramienta Solver en una hoja de cálculo de Excel.

$$
\mu=\mu \max \cdot \frac{\mathrm{s}}{\mathrm{Ks}+\mathrm{Ki} \cdot \mathrm{S}^{2}}
$$

Donde:

$\mu=$ Velocidad específica de crecimiento (AME)

$\mu$ max $=$ Velocidad máxima de la actividad

$\mathrm{S}=$ Sustrato RSO (gSVT)

$\mathrm{Ki}=$ Constante de inhibición del sustrato

$\mathrm{Ks}=$ Constante de saturación del sustrato

Figura 7. Ajuste del modelo de Haldane en la inhibición por sustrato de las bacterias acetoclásticas.

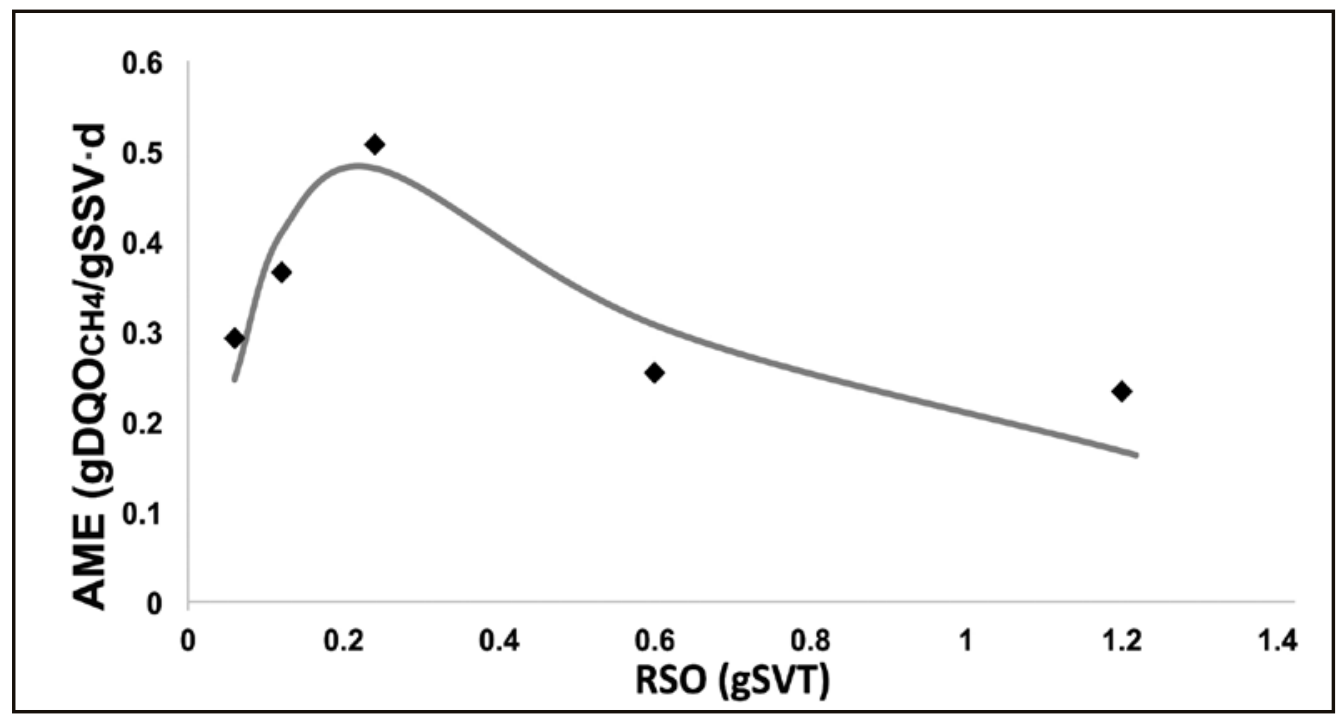

\section{Efecto de los niveles de inóculo en la producción de metano}

En la figura 8 se observa el efecto de la adición de biomasa sobre la producción de metano de los residuos orgánicos. La cantidad de materia orgánica utilizada para cada ensayo fue de 0.24 gSVT. Mientras que la cantidad de inóculo varió de 0 a $5.66 \mathrm{gSSV}$. La producción de metano es proporcional a los niveles de biomasa. Sin biomasa, se observó una baja producción de metano de $11 \mathrm{~mL}$ a los 24 días, mientras que en niveles superiores (1.66 a $5.66 \mathrm{gSSV}$ ) se presentó un aumento en la producción de metano logrando una producción máxima de $134 \mathrm{~mL}$ en el día 24 .

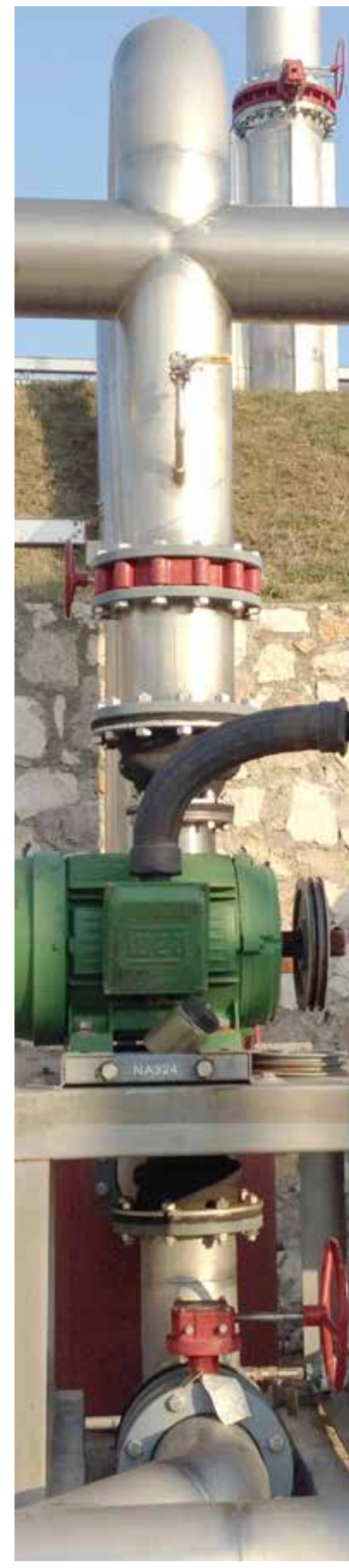




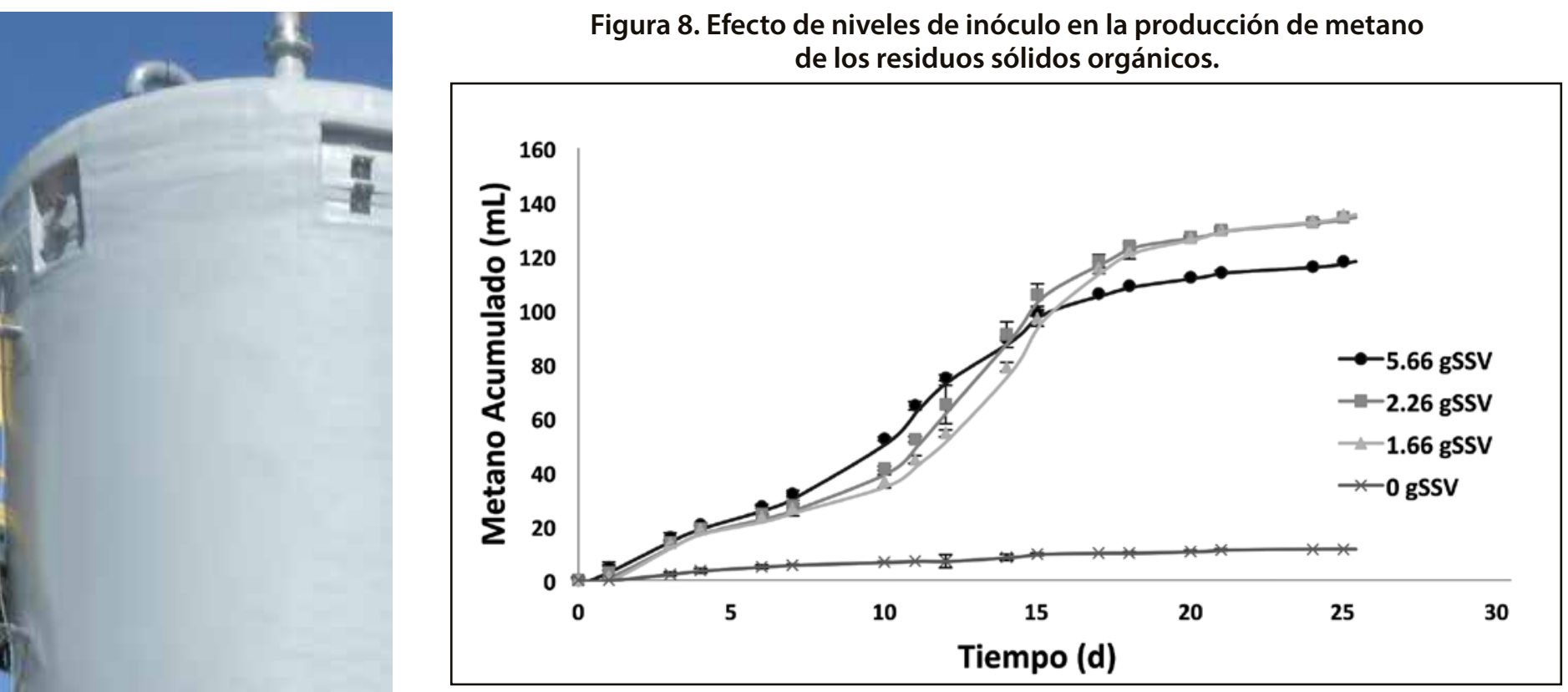

Con base en las producciones exponenciales de metano observado de la figura 8, se determinaron las actividades metanogénicas específicas para cada una de las concentraciones probadas. Con el objetivo de observar el efecto de los niveles de inóculo en las actividades. Sin adición del inoculo la AME fue casi nula con un valor de 0.072 $\mathrm{gDQO}_{\mathrm{CH}_{4}} / \mathrm{gSSV} \cdot d$, y se incrementó a 0.67 al aumentar el nivel de biomasa a $1.13 \mathrm{gSSV} / \mathrm{L}$, posteriormente la actividad se estabilizó en $0.76 \mathrm{gDQO}{ }_{\mathrm{CH} 4} / \mathrm{gSSV} \cdot \mathrm{d}$, en los subsecuentes niveles probados, por lo tanto, es recomendable trabajar con niveles de biomasa alrededor de $1.5 \mathrm{gSSV} / \mathrm{L}$.

Figura 9. Efecto de los niveles de inoculo en la actividad metanogénica específica durante la producción de metano de los RSO.

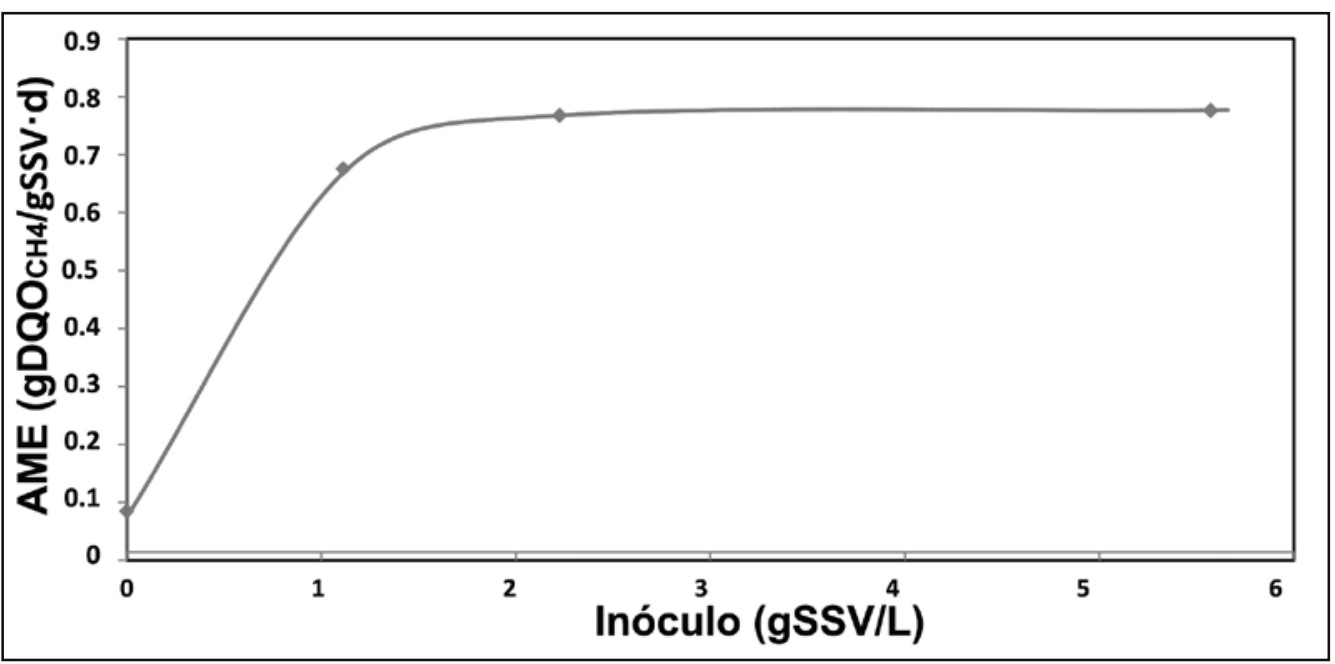

\section{CONCLUSIONES}

La caracterización de los RSO presentó un elevado contenido de humedad lo cual es favorable para solubilizar la materia orgánica susceptible a la biometanización. También presentó un contenido rico en materia orgánica y nitrógeno entre otros elementos que satisfacen las necesidades de crecimiento y producción de metano de las bacterias anaerobias. 


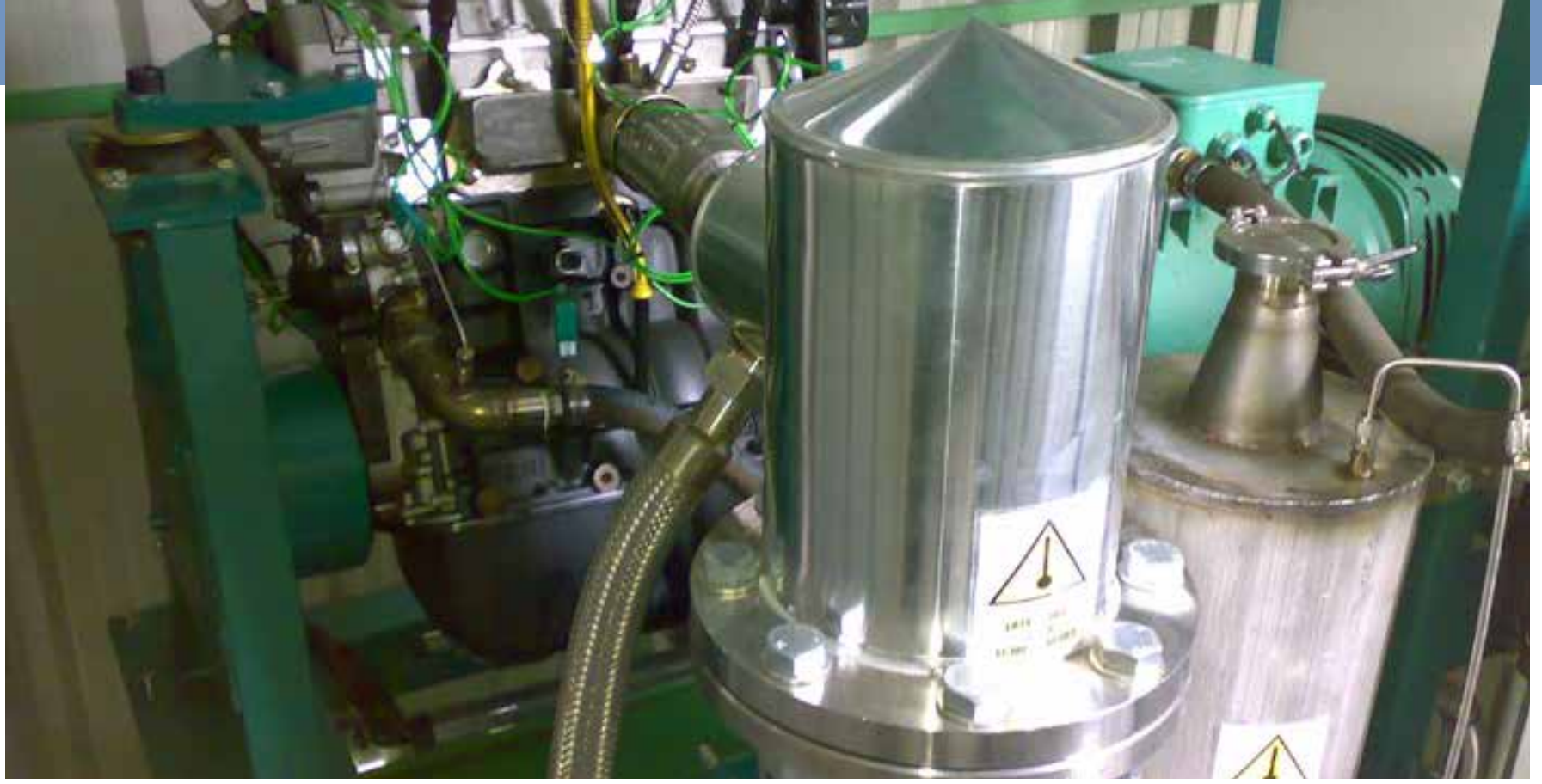

El potencial bioquímico de metano es un método valioso para evaluar la máxima producción de metano de los RSO además de su biodegradabilidad, así como su tasa específica de biometanización. La fracción orgánica de los residuos sólidos urbanos del comedor universitario tiene un potencial de producción de $71 \mathrm{~m}^{3}$ de metano por tonelada de RSO lo cual es superior a lo reportado en la literatura.

Las altas concentraciones de los RSO (0.6-1.2 gSVT) afectó la actividad de las bacterias metanogénicas acetoclásticas por lo que se debe cuidar la carga orgánica utilizada para evitar inhibición por sustrato de éstas bacterias las cuales son las que realizan el $70 \%$ de la producción de metano.

Es importante utilizar una cantidad adecuada de inóculo para optimizar el proceso. La producción de metano incrementó con el aumento de los niveles de biomasa. Los resultados de este trabajo se demuestra que se requiere una baja cantidad de biomasa (1.5 gSSV/L) y en concentraciones superiores no se favoreció el proceso.

La producción de metano de los RSO es viable para su utilización como fuente de energía y a su vez contribuye a la sustentabilidad ambiental. Los resultados de las pruebas del potencial bioquímico de metano pueden ser utilizados para la calibración de modelos matemáticos y simular los procesos de digestión con el fin de predecir el comportamiento de digestores a escala real.

La biometanización presenta resultados prometedores que deben ser objeto de mayores estudios como el seguimiento de metabolitos primarios y secundarios durante la metanización, así como investigar nuevos diseños para optimizar el proceso.

\section{RECONOCIMIENTOS}

Al Departamento de Ingeniería Química y Metalurgia de la Universidad de Sonora, por otorgar el espacio y los apoyos para realizar este experimento; a la profesora
Q.B. María Elena Ochoa Landín por su apoyo en las técnicas analíticas para la caracterización de los residuos.

\section{BIBLIOGRAFIA}

[1] Elías X. (2009). Reciclaje de Residuos Industriales, residuos sólidos urbanos y fangos de depuradora. 2da edición.

[2] López M., Espinoza M., Martinez V., Ramos C., Pellón A. (2003). Desarrollo y Tendencias en la Gestión de los Residuos Sólidos Urbanos. Centro Nacional de Investigaciones Científicas.

[3] JRC (2011). Supporting Environmentally Sound Decisions for Bio-Waste Management.-A practical guide to Life Cycle Thinking (LCT) and Life Cycle Assessment (LCA) in the context of bio-waste management. JRC Scientific and Technical Reports. European Union. Joint Research Centre (JRC). Institute for Environment and Sustainability (IES).

[4] Canvinato, C., Bolzonella, D., Pavan, P., Fatone, F., Cecchi, F. (2013). Mesophilic and thermophilic anaerobic co-digestion of waste activated sludge and source sorted biowase in pilot and full-scale reactors. Renewable Energy (55) 260-265.

[5] Juanga J. P. (2005). Optimizing Dry Anaerobic Digestion of Organic Fraction of Municipal Solid Waste. Master Thesis. Asian Institute of Technology. Thailand 2005.

[6] ZEEUW.W (1987). Granular sludge in USAB reactors, Proceding of the gasmat workshop. Lungstem Netherlands.

[7] Sterling (1989). (Citado de: López G., Método no convencional de medición de gases en la digestión anaerobia. Estimación del porcentaje de metano presente en el biogás) [En línea] [Consulta: 28 de junio de 2014]. Disponible en: http:// cidc.udistrital.edu.co/investigaciones/documentos/ revistacientifica/rev5/vol1/1Gases.pdf.

[8]. Speece R. E. (1996). Anaerobic Biotechnology for Industrial wastewaters Archae press USA.

[9] Thomas S., Burns R., Raman R., Moody L. (2010). "Approaches for Selecting Anaerobic Digestion Co-Substrates for a FullScale Beef Manure Digester Using Biochemical Methane Potentials and Anaerobic Texicity Assays". Agricultural and Biosystems Engineering Conference Proceedings and Presentations. Paper 57.

[10] Rigo M., Monte R., Vidal J., Coelho N., Gaspar R. (2010). Catechol Biodegradation Kinetics Using Candida Parapsilosis. Universidae Estadual de Campinas. SP Brasil.

[11] Autenrieth R. L., Bonner J.S., Akgerman A.,Okaygun M. y McCreary E.M. (1991). Biodegradation of phenolic wastes. J. Hazard. Mat. $28: 29-53$. 